\title{
Association of snuff use with chronic bronchitis among South African women: implications for tobacco harm reduction
}

\author{
0 A Ayo-Yusuf, ${ }^{1}$ P S Reddy, ${ }^{2}$ B W van den Borne ${ }^{3}$
}

\begin{abstract}
${ }^{1}$ Department of Community Dentistry, School of Dentistry, University of Pretoria, South Africa; ${ }^{2}$ Health Promotion Research and Development Unit, Medical Research Council, Cape Town, South Africa;

${ }^{3}$ Department of Health

Education and Health Promotion,

Maastricht University,

Maastricht, The Netherlands

Correspondence to:

Dr 0 A Ayo-Yusuf, Department

of Community Dentistry, School of Dentistry, Oral and Dental

Hospital, University of Pretoria

P.0. Box 1266, Pretoria 0001,

South Africa; lekan.ayoyusuf@

up.ac.za
\end{abstract}

Received 28 June 2007

Accepted 12 November 2007

\begin{abstract}
Objective: Nasal use of snuff is the predominant form of tobacco use among black South African women. This study examines the association between snuff use and chronic bronchitis (CB) among black South African women.

Design: The study investigated a nationally representative sample of 4464 black South African women $\geqslant 25$ years old who participated in the 1998 South African Demographic and Health Survey. Data on participants' tobacco use patterns, medical history and other relevant factors were obtained through an interviewer-administered questionnaire. Peak expiratory flow rates (PEFR) were also measured. Data analysis included $\chi^{2}$ statistics, Student $t$ tests and multiple logistic regression analysis.

Outcome measure: $\mathrm{CB}$, defined as reporting a productive cough for $\geqslant 3$ months/year for at least 2 successive years
\end{abstract}

Results: The prevalence of current snuff use was 16.1\% $(n=719)$. Compared to non-users of snuff, snuff users were not only more likely to present with a history of tuberculosis (TB) (23.3\% vs 15.9\%; $p=0.06)$, but they were also more likely to present with CB $(5.3 \%$ vs $2.8 \%$; $p<0.01$ ) and a lower PEFR (275 litres/min vs 293 litres/ min; $p<0.01$ ). Significant determinants of CB included snuff use $>8$ times/day (odds ratio (OR) $2.86,95 \% \mathrm{Cl}$ 1.17 to 7.02 ), a history of $\mathrm{TB}(\mathrm{OR} 7.23,95 \% \mathrm{Cl} 4.02$ to 13.03), current smoking (OR 2.84, 95\% $\mathrm{Cl} 1.60$ to 5.04 ) and exposure to smoky cooking fuels (OR 1.98, 95\% Cl 1.32 to 2.96).

Conclusions: These data suggest that snuff use, in the form predominantly used in South Africa, increases the risk of CB. This challenges the idea that snuff may be a much less harmful alternative to smoking in South Africa.

Both cigarette smoking and smokeless tobacco (SLT) or snuff use are common in South Africa, with an estimated national prevalence of $24.6 \%$ and $6.7 \%$ respectively in $1998 .{ }^{1}$ Unlike in most western countries, about $80 \%$ of snuff is taken nasally in South Africa. While fewer than 1\% of South African men use snuff, among black South African women snuff is the predominant form of tobacco use, with a prevalence of $13.2 \%$ among women in 1998 compared to the 5.3\% prevalence of smoking among women. ${ }^{1}$ Of particular concern is a recent report of the World Health organization (WHO) global youth tobacco survey, which suggests that in 2002 the prevalence of snuff use among South African adolescents was 14.5\%. ${ }^{2}$

There are traditional homemade and a limited range of commercial/industrialised SLT products on the South African market. The nicotine delivery potentials of the popular SLT products have been previously published. ${ }^{3}$ Snuff, available as fine powdered tobacco, is much less expensive than cigarettes in South Africa; a can of snuff typically costs 3 Rands (US\$0.40) compared to 14 Rands (US\$2.00) for a pack of cigarettes. The concentration of free base nicotine available for absorption by the users of South African SLT products previously tested was comparable and sometimes greater than that obtainable from commercial filtered cigarettes, depending on the heaviness of use. The most popular traditional and industrialised products on the South African market, typically with a moisture content of about $40 \%$, are used both by oral and nasal application. The route of delivery therefore does not appear to be product-specific in South Africa, but may be dependent on cultural preferences as suggested by a recent study finding. ${ }^{4}$

Most of the existing literature on the health effects of snuff comes from western nations, particularly Sweden, where most users are Caucasian male snuff dippers. Since consistent association between snuff and major diseases is lacking (particularly in developed nations), snuff is widely considered to be considerably less harmful than cigarettes and snuff is therefore promoted as a reduced-harm product. ${ }^{5}$ Although the snuff products commonly used in South Africa may differ from those used in such western countries, ${ }^{6}$ in South Africa, too, snuff use is perceived by some adolescents to be a safer alternative to cigarettes.? New Zealand is currently considering allowing the sale of nasal snuff as part of a harm-reduction strategy. The strategy has been proposed by some members of the public health community. ${ }^{8}$ Nasal snuff is also reported to be making its way back onto the English market as a result of the recent ban on public smoking. ${ }^{9}$

In fact, long-term use of certain types of snuff has been associated with adverse reproductive outcomes ${ }^{10}$ and the development of oropharyngeal and upper respiratory tract cancers. ${ }^{10-13}$ The results of recent large-scale studies have suggested that compared to non-use of any tobacco product, snuff use is associated with an increased risk of pancreatic cancer, ${ }^{14}$ higher mortality from all causes, ${ }^{15} 16$ and an increased risk of lung cancer mortality ${ }^{17}$ and lung cancer incidence among elderly American women. ${ }^{18}$ Snuff use and chronic bronchitis (CB) have also previously been reported as strong risk factors for lung cancer in a Moroccan population, ${ }^{19}$ but the association between snuff use and $\mathrm{CB}$ has not been previously reported. 
None of the reviews of the earlier literature on the health effects of oral ${ }^{6}$ or nasal ${ }^{20}$ use of snuff has explored a link between snuff use and $\mathrm{CB}$, despite the fact that even during nasal application snuff dust can conceivably be inhaled, and snuff has been suggested as a source of bacteria in $\mathrm{CB} .{ }^{21} \mathrm{~A}$ more recent study has also questioned the microbiological safety of some finished snuff products on the South African market. ${ }^{22}$ The majority of users in South Africa use snuff with high nicotinedelivery capabilities, ${ }^{3}$ and nicotine has been suggested to be a potent bronchial gland stimulant. ${ }^{23}$ This study therefore sought to determine the association between snuff use and $\mathrm{CB}$ among black South African women.

\section{METHOD}

\section{Data source and study design}

Data for this study were obtained from black South African women aged 25 years and older $(n=4464)$ who participated in the first (and so far the largest publicly available) South African Demographic and Health Survey (SADHS), a nationally representative, cross-sectional household questionnaire survey conducted between February and September 1998. Questionnaires were prepared in all 11 of South Africa's official languages and back translation was used to check for consistency of meaning. The 1998 SADHS used a stratified, two-stage probability sample design. The methods used to standardise data collection, and the interview and consent procedures have been previously published. ${ }^{124}$ The protocol for the SADHS was approved by the ethics committee of the South African Medical Research Council.

\section{CB risk-factor assessment and definitions}

The questionnaire was administered by trained fieldworkers. It inquired into socio-demographic characteristics and past medical history, including a past history of tuberculosis (TB) infection. An asset index, which is a measure of socioeconomic status, was derived from a composite score of five household items (electricity, television, telephone, refrigerator and washing machine) owned by respondents as identified in a factor analysis for inclusion. The respondents answered "yes" (code 1) or "no" (code 0) to each of the listed household items on the questionnaire. The scale can be considered to be very reliable, because it has a Cronbach alpha score of 0.80 . The scores that were obtained were then ranked to classify the respondents into three socioeconomic categories.

Respondents who answered "yes" to the question "Have you ever smoked tobacco?" were categorised as "ever" smokers. Those who said that they had never smoked but that they may have used snuff were classified as "never" smokers. "Ever" smokers were further categorised as "current regular smokers" if they said that they currently smoke daily or occasionally, and as "ex-smokers" if they said that they had previously smoked daily, but did not smoke at all at the time of the interview. Respondents who said they currently take snuff were asked about average daily frequency of snuff use. There was no question on the past history of snuff use in the 1998 SADHS. Other exposure and personal history variables included occupational exposure to dust/fumes/strong smells, domestic fuel exposure and domestic and work exposure to second-hand smoke.

Data on the symptomology of $\mathrm{CB}$ were based on a series of four standardised questions on chronic productive coughing, adapted from the internationally used British Medical Research Council Questionnaire. ${ }^{25}{ }^{26} \mathrm{CB}$ was defined as presenting with a history of a complex of symptoms including a chronic cough with phlegm every day for at least 3 months of the year for at least 2 successive years. As part of an effort to internally validate the questionnaire diagnosis of $\mathrm{CB}$, each participant's peak expiratory flow rate (PEFR) was tested at his/her home using a Tru-Zone mini-peak flow meter (Trudell Medical International, London, Ontario, Canada).

\section{Statistical analysis}

All statistical analyses were done using STATA Release 8 (Stata Corporation, College Station, Texas, USA) with appropriate weight adjustments made for selection probabilities and the complex sample design of the SADHS. Data were summarised as prevalence rates (\%) with 95\% confidence intervals. Statistical comparisons were made between the PEFR and CB prevalence among current and non-current snuff users. Group differences were assessed using $\chi^{2}$ statistics and independent sample Student t tests. Multiple logistic regression models were constructed to determine the independent association between different intensities of snuff use and $\mathrm{CB}$ prevalence, while controlling for the influence of age, smoking duration and other covariates identified in both published literature ${ }^{24}$ and our bivariate analysis as being significantly associated with snuff use and $\mathrm{CB}$. Guided by the previously reported frequency of snuff use, $^{27}$ for the purpose of analyses, respondents were categorised as those who do not currently use snuff, those who use 1-8 times/day and those who use $>8$ times/day. As there were too few women snuff users currently smoking $(n=4)$ and also too few ex-smokers currently using snuff $(n=10)$, these individuals were grouped as smokers and ex-smokers respectively during subsequent statistical analyses. Sensitivity analysis showed that exclusion of these categories of snuff users did not change the parameter estimates obtained in this study. Statistical significance was set at $\mathrm{p}<0.05$.

\section{RESULTS}

Of the study sample, $16.1 \%(n=719)$ reported current snuff use and $3.2 \%(n=142)$ reported CB. Subjects who met the questionnaire diagnostic criteria for CB had significantly lower mean PEFR values than those who did not (237 litres/min vs 292 litres/min; $\mathrm{p}<0.01$ ). The mean difference was 55 litres/min (95\% CI 38-71). The prevalence of both snuff use and of $\mathrm{CB}$ were lowest among the most educated respondents and those in the highest socioeconomic class, and the incidence of $\mathrm{CB}$ was highest among those who reported a past history of TB (table 1). Compared to those without a history of $\mathrm{TB}$, respondents with a history of TB were also more likely to be current snuff users, (23.3\% vs $15.9 \%$; $p=0.06)$.

Current snuff users and current smokers were more likely to report $\mathrm{CB}$ than non-users of tobacco. Compared to those not currently using snuff, current snuff users were also more likely to present with a lower PEFR (275 litres/min vs 293 litres/min; $\mathrm{p}<0.01)$. A history of domestic and/or occupational exposure to second-hand smoke was not significantly associated with CB (age-adjusted odds ratio (OR) 1.01, 95\% CI 0.67-1.54), but occupational exposure to dust/fumes/strong smells and domestic exposure to smoky cooking fuels were strongly associated with both $\mathrm{CB}$ and snuff use in both the bivariate and multivariate analyses. Even after controlling for these potential confounders in a multivariate analysis, although the effect of snuff use was found to be grossly attenuated, a dose-response relationship remained between snuff use and CB (table 2). Snuff use of $>8$ times/day remained significantly associated with $C B$ 
Table 1 Prevalence of snuff use and chronic bronchitis relative to socio-demographic and exposure characteristics

\begin{tabular}{|c|c|c|}
\hline Characteristics & Snuff use $(\%)^{*}$ & Chronic bronchitis $(\%)^{*}$ \\
\hline Prevalence $(95 \% \mathrm{Cl})$ & $16.1(14.6-17.6)$ & $3.2(2.6-3.8)$ \\
\hline \multicolumn{3}{|c|}{ Asset index (tertiles) $(n=4447)$ : } \\
\hline Poorest & 18.5 & 5.6 \\
\hline Middle & 16.6 & 2.4 \\
\hline Richest & 10.6 & 1.3 \\
\hline $\mathrm{p}$ Value & $<0.001$ & $<0.001$ \\
\hline \multicolumn{3}{|l|}{ Education level $(n=4449)$ : } \\
\hline None & 24.5 & 5.6 \\
\hline $1-7$ years schooling & 16.6 & 3.3 \\
\hline $8-12$ years schooling & 11.5 & 1.8 \\
\hline$>12$ years schooling & 2.5 & - \\
\hline $\mathrm{p}$ Value & $<0.001$ & $<0.001$ \\
\hline \multicolumn{3}{|l|}{ Residence $(n=4464)$ : } \\
\hline Urban & 15.3 & 2.2 \\
\hline Rural & 16.9 & 4.1 \\
\hline $\mathrm{p}$ Value & 0.30 & $<0.01$ \\
\hline \multicolumn{3}{|c|}{ History of tuberculosis ( $\mathrm{n}=4451$ ): } \\
\hline Never & 15.9 & 2.8 \\
\hline Ever & 23.3 & 21.1 \\
\hline $\mathrm{p}$ Value & 0.06 & $<0.001$ \\
\hline \multicolumn{3}{|l|}{ Cooking fuel used $(n=4455)$ : } \\
\hline Gas/electricity/paraffin & 15.2 & 2.3 \\
\hline Wood/coal/dung (smoky) & 19.1 & 6.2 \\
\hline $\mathrm{p}$ Value & 0.02 & $<0.001$ \\
\hline \multicolumn{3}{|c|}{ Occupational exposure $(n=4455)$ : } \\
\hline Never & 15.8 & 2.8 \\
\hline Ever & 21.7 & 5.8 \\
\hline $\mathrm{p}$ Value & $<0.01$ & $<0.001$ \\
\hline \multicolumn{3}{|l|}{ Smoking status $(n=4464)$ : } \\
\hline Never smoked & 17.1 & 2.9 \\
\hline Ex-smoker & 14.9 & 1.5 \\
\hline Current smoker & 1.3 & 7.3 \\
\hline $\mathrm{p}$ Value & $<0.001$ & $<0.001$ \\
\hline \multicolumn{3}{|l|}{ Snuff use status $(n=4464)$ : } \\
\hline Non-user & & 2.8 \\
\hline Use 1-8 times/day & & 4.3 \\
\hline Use $>8$ times/day & & 11.7 \\
\hline p Value & & $<0.01$ \\
\hline
\end{tabular}

Sample sizes for some variables do not sum to the total (4464) due to missing data. *Weighted prevalence estimates.

(fully adjusted $\mathrm{OR}=2.86,95 \%$ CI 1.17-7.02) and so was current smoking (fully adjusted OR 2.84, CI 1.60-5.04), irrespective of the intensity of smoking. However, a non-linear dose-response was observed between the risk of $\mathrm{CB}$ and the reported number of cigarettes smoked per day (CPD) (table 2). The median CPD was four. Compared to never smokers, those who reported smoking 1-4 CPD had a higher risk of presenting with CB than those who reported smoking $>4 \mathrm{CPD}$.

\section{DISCUSSION}

This study demonstrates the first findings of a significant association between snuff or SLT use and CB. These findings also demonstrate common risk factors for snuff use and a diagnosis of CB, suggesting that snuff users in South Africa could be at a cumulative disadvantage for developing chronic airway diseases. Also significant is this study's support of a previous report, ${ }^{24}$ which suggested that a history of TB infection was strongly associated with CB. In addition, our study suggests that snuff users are more likely to present with a history of $\mathrm{TB}$. This observation calls for further investigation of the potential risk of snuff users spreading $\mathrm{TB}$ or being at high risk of contracting TB, especially in countries like South Africa which have a relatively high prevalence of TB. Snuff users and those suffering from $\mathrm{CB}$ are also more likely to be poor, uneducated women, who are more likely to cook with smoky fuels and work in conditions where they are exposed to dust, fumes and/or strong smells. Significantly, however, even after controlling for these potential confounders, this study shows that current daily heavy ( $>8$ times/day) snuff users, but not less frequent users, had almost three times greater odds of developing $\mathrm{CB}$ when compared to non-users of snuff. By contrast, albeit consistent with the literature, ${ }^{28}$ those smoking even at low rates of 1-4 CPD as compared to never smokers were significantly more likely to present with a history of $\mathrm{CB}$.

Although somewhat consistent with the findings of a similar study that reported the correlates of occurrence of CB among the general population of South African women, ${ }^{24}$ the unexpected finding that black South African women that reported smoking 1-4 CPD had higher odds of developing CB than those smoking $>4$ CPD may be related to compensatory changes in smoking behaviour. This view is supported by findings of a recent study that showed a similar unexpected non-linear relationship between changes in lung function and reduced smoking rates among smokers with early chronic obstructive pulmonary disease (COPD) ${ }^{29}$ It is indeed possible that heavy smokers that experienced early symptoms of COPD may have opted to reduce their smoking rates, but because of compensatory smoking (eg deeper and more frequent puffs) would effectively still be exposed to similar or even greater levels of cigarette toxins as before the reduction. Nonetheless, the unexpected observation of the larger impact of lower smoking rate on lung health in the current study may also be related to reporting bias. In a society where smoking by black South African women in particular is traditionally viewed as socially unacceptable, it is conceivable that heavier smokers may find it more socially desirable to report lower smoking rates.

Although it is still a possibility that uncontrolled residual confounders may explain the observed association of snuff use with $\mathrm{CB}$, it is biologically plausible that nasal use of snuff could lead to $C B$. A previous report notes nasal symptoms associated with nasal mucosal changes in snuff users $^{30}$ and these nasal symptoms in turn have been associated with increased occurrence of CB. ${ }^{31}$ Furthermore, this study's finding would be consistent with that of a previous case study of $\mathrm{CB}$, which suggests that nasal use of snuff could have been the source of the bacteria in $\mathrm{CB} .^{21}$

Contrary to a recent suggestion that smoke constituents other than nicotine may be responsible for increased pulmonary airway resistance, ${ }^{32}$ this study's findings, supported by results from other studies, ${ }^{23}{ }^{33}{ }^{34}$ suggest that the nicotine in snuff could be associated with hyper-secretion of local bronchial glands and could therefore contribute to $\mathrm{CB}$, especially in the presence of bacterial infection. Nicotine has also been shown to prolong the survival of neutrophils, ${ }^{35}$ the accumulation of which in the lungs has been implicated in the pathogenesis of $\mathrm{CB} .{ }^{36}$ The current study's findings may differ from those of other studies because the snuff products used in South Africa have a relatively high $\mathrm{pH}$ and thus a higher nicotine-delivery capability than the SLT products commercially available elsewhere. ${ }^{3}$ It is however, pertinent to note that Bolinder et $a^{37}$ also previously reported a significantly increased risk for reporting symptoms of COPD in a Swedish cohort of oral SLT users, as compared to non-users. Considering that similar respiratory problems have been noted among tobacco factory workers, ${ }^{38}{ }^{39}$ although to a lesser degree, it is also possible that respirable snuff dust particles may 
Table 2 Multiple logistic regression model for chronic bronchitis $(n=4425)$

\begin{tabular}{|c|c|c|}
\hline & Crude odds ratio $(95 \% \mathrm{Cl})$ & Fully adjusted* odds ratio $(95 \% \mathrm{Cl})$ \\
\hline \multicolumn{3}{|l|}{ Snuff use: } \\
\hline Never/none-current & 1 & 1 \\
\hline 1-8 times/day & $1.56(0.96$ to 2.55$)$ & 1.18 (0.69 to 2.03$)$ \\
\hline$>8$ times/day & 4.63 (2.09 to 10.22$)$ & 2.86 (1.17 to 7.02$)$ \\
\hline \multicolumn{3}{|l|}{ Smoking status: } \\
\hline Never smoked & 1 & 1 \\
\hline Ex-smoker & 0.48 (0.12 to 1.99$)$ & 0.35 (0.09 to 1.46$)$ \\
\hline 1-4 CPD & 2.96 (1.43 to 6.11$)$ & 3.15 (1.44 to 6.89$)$ \\
\hline$>4 \mathrm{CPD}$ & 2.31 (1.16 to 4.59$)$ & $2.54(1.26$ to 5.14$)$ \\
\hline \multicolumn{3}{|l|}{ Asset (tertile) index: } \\
\hline Lowest rank (poorest) & 1 & 1 \\
\hline Middle & $0.44(0.30$ to 0.66$)$ & 0.69 (0.45 to 1.04$)$ \\
\hline Highest rank & $0.24(0.10$ to 0.63$)$ & $0.45(0.17$ to 1.15$)$ \\
\hline \multicolumn{3}{|l|}{ Tuberculosis: } \\
\hline Never & 1 & 1 \\
\hline Ever & 9.41 (5.41 to 16.38$)$ & 7.23 (4.02 to 13.03$)$ \\
\hline \multicolumn{3}{|l|}{ Cooking fuel: } \\
\hline Gas/Electricity/Paraffin & 1 & 1 \\
\hline Smoky fuels & $2.82(1.92$ to 4.14$)$ & $1.98(1.32$ to 2.96$)$ \\
\hline \multicolumn{3}{|c|}{ Occupational exposure to irritants: } \\
\hline Never & 1 & 1 \\
\hline Ever & $2.12(1.31$ to 3.43$)$ & $1.95(1.20$ to 3.17$)$ \\
\hline
\end{tabular}

*In addition to these covariates, the model also controlled for age.

$\mathrm{CPD}$, cigarettes per day

inadvertently be inhaled during handling of loose snuff for oral application. This may over time invoke inflammatory responses in the airway similar to that associated with CB. Conceivably, dust inhalation would be less of a possibility if the snuff powder were enclosed, as is the case with the modern oral SLT products that are portion-packed in teabag-like pouches. This view is further supported by a recent analysis of spit tobacco associated mortality, which demonstrated a significant association with increased risk for mortality from COPD among users in a 19591972 US cohort, but failed to detect significant mortality risk from COPD among those in the 1982-2000 cohort. ${ }^{16}$ The later cohort presumably included those using newer SLT products as it coincides with the period when SLT had been introduced in pouches. Therefore, the findings of our study may not be generalisable to the use of other SLT products or other forms of nicotine-delivery vehicles such as nasal sprays, which may also have different nicotine pharmocodynamics.

It has been suggested that different SLT products pose disease risks of different severity. ${ }^{40}$ The modern low-nitrosamine oral moist SLTs, some of which have recently been introduced onto the South African market, have been reported to pose considerably lower health risks compared to smoking. ${ }^{6}$ However, with the strong tradition of nasal use of snuff in South Africa, and the continued sale of snuff for nasal delivery by the same manufacturers of these modern oral SLT products, it remains to be seen if current marketing of the new oral SLTs will encourage South African smokers to switch to these oral SLT products or even to using the much cheaper traditional SLT products for nasal application. A major manufacturer of snuff in South Africa is also currently advocating that smokers switch to nasal SLT products in New Zealand. However, limited information is available on the health risks of nasal use of snuff, so most of the arguments made for switching to nasal snuff to reduce health risks are based on studies on oral moist snuff, ${ }^{8}$ which may be a distinctly different SLT product.

This study's finding that a current frequent snuff user's risk of developing $\mathrm{CB}$ is the same as that of a current smoker weakens arguments that nasal snuff use may be sufficiently less harmful than smoking to be worth promoting as an alternative. Taking into account the risk-use equilibrium, ${ }^{41}$ promoting such a strategy in the studied population could be a potentially risky population experiment, given that the current number of black South African women snuff users is already almost three times higher than the number of smokers. Furthermore, given that any suggestion of the relative safety of any snuff product in a fairly uneducated population could inadvertently encourage continued or increased snuff use, such a harm-reduction strategy could potentially increase total tobacco-related disease in the studied population, especially since a significant decline in smoking rates has already been observed in this population due to current governmental policy. ${ }^{142}$ Such a strategy would also be problematic in parts of Africa and India where the nasal use of snuff is still relatively common and the relatively high cost of modern oral SLT products may be prohibitive. Considering that these third-world populations of snuff users may be larger in number than those of current SLT users in developed countries, the findings of this study suggest that future policy debates on SLT as a harm-reduction strategy need to be broadened to include the implications of such a strategy for populations outside developed countries.

\section{Study limitations}

Our study findings are subject to some limitations. Firstly, as mentioned above, the findings may not be generalisable to other SLT products. Secondly, the study relies on self-reporting of tobacco use and CB. The participants' responses are therefore potentially subject to reporting bias, especially in respect of smoking, which is generally regarded as a social taboo among black South African women. It is therefore possible that such reporting bias may have weakened the association reported between smoking and $\mathrm{CB}$. Furthermore, the responses to questions used for $\mathrm{CB}$ diagnosis may be subject to recall bias. Nevertheless, the criteria used for $\mathrm{CB}$ diagnosis are similar to those used in many other national surveys, with which our 


\section{What this paper adds}

Only limited information is available about health risks associated with the use of smokeless tobacco (SLT) products other than those currently available in Europe and North America. However, the harm-reduction debate extends to populations as far removed from such markets as South Africa and New Zealand, where nasal use of snuff is either currently the predominant form of SLT use or the form currently being advocated. This study provides useful information needed to improve the current basis for risk assessment of SLT use in populations outside of Europe.

This study's findings, which suggest that heavy snuff use is equally as likely to be associated with chronic bronchitis as smoking in the studied South African population, challenge any public health strategy that may want to promote a switch to SLT use as a public policy response for the reduction of tobaccorelated diseases in South Africa.

results are thus comparable. Moreover, in our study, CB diagnosis was cross-validated with PEFR measurements. Thirdly, because this was a cross-sectional study, reverse causality is possible, although not likely. Accordingly, any inference about causality based on the current study should be made with caution. Snuff use must be confirmed as a true risk factor in longitudinal studies that take into account the temporal order of events. Fourthly, the SADHS did not include relevant information such as the exact form of SLT use, past history of use and the lifetime duration of use. Therefore, age (which is expected to correlate with years of use) was used as a covariate in all the analyses, irrespective of the level of statistical significance detected. Conceivably, if some of the study participants were in fact snuff-dippers or if a significant proportion of non-current users of snuff were ex-users of snuff, these may have attenuated rather than inflated the strength of the association reported for current snuff use in this study. Lastly, the data that were used are somewhat dated. However, considering that the biological relationship hypothesised between snuff and bronchitis is not time-dependent, this is not likely to influence the study findings significantly, except if the snuff products used before 1998 differed from those currently in use. However, the reported $\mathrm{pH}$ of a commonly used traditional snuff mixture ${ }^{43}$ and that of the most popular industrialised brand tested in the past (unpublished results) are similar to the $\mathrm{pH}$ of similar products tested more recently. ${ }^{3}$ This implies that the nicotine-delivery capability of these products are also similar. Thus the nicotine-delivery potential of snuff products currently in use is not likely to be considerably lower than those used prior to 1998.

Despite these limitations, this study provides useful information about the risk of SLT products used by populations outside Europe.

\section{CONCLUSIONS}

Although further investigation is needed on the exact biological mechanisms, this study demonstrates for the first time that snuff use, in the form predominantly used in South Africa, increases the risk for $\mathrm{CB}$. This challenges the idea that snuff may be a much less harmful alternative to smoking in South Africa and in particular, among black South African women. The study findings also highlight the need for public health interventions that discourage the adoption of any form of tobacco use and promote tobacco use cessation, particularly among South African adolescents.
Acknowledgements: The 1998 SADHS survey was funded by the South African National Department of Health under the co-ordination of the Medical Research Council of South Africa. Data for this study were obtained with permission from the National Department of Health through the South African Data Archives (SADA) hosted at the South African National Research Foundation (NRF).

Funding: The preparation of this manuscript was supported by grant received from the Cancer Association of South Africa (CANSA).

Competing interests: None.

\section{REFERENCES}

1. Steyn K, Bradshaw D, Norman R, et al. Tobacco use in South Africans during 1998: the first demographic and health survey. J Cardiovasc Risk 2002;9:161-70.

2. Swart D, Reddy P, Panday S, et al. The 2002 Global Youth Tobacco Survey (GYTS): the 2nd GYTS in South Africa - a comparison between GYTS (SA) 1999 and GYTS (SA) 2002. Cape Town, South Africa: South African Medical Research Council, 2004

3. Ayo-Yusuf $\mathbf{0 A}$, Swart TJP, Pickworth WB. Nicotine delivery capabilities of smokeless tobacco products and implications for control of tobacco dependence in South Africa. Tob Control 2004;13:186-9.

4. Ayo-Yusuf $\mathbf{0 A}$, Peltzer K, Mufamadi J. Traditional healers' perception of smokeless tobacco use and health in the Limpopo Province of South Africa. Subst Use Misuse 2006;41:211-22.

5. Stratton K, Shetty P, Wallas P, et al. Clearing the smoke: assessing the science base for tobacco harm reduction. Washington DC, USA: National Academy of Sciences, National Academy Press, 2001

6. Critchley JA, Unal B. Health effects associated with smokeless tobacco: a systematic review. Thorax 2003;58:435-43.

7. Peltzer K. Smokeless tobacco and cigarette use among black secondary school students in South Africa. Subst Use Misuse 2003;38:1003-16.

8. SmokeLess New Zealand. Nasal snuff - a traditional, less harmful way to use tobacco. http://www.smokeless.org.nz/nasalsnuffMay06.pdf (accessed 5 Jun 2007).

9. BBC News Magazine. Sniffing out the smoking ban. http://news.bbc.co.uk/1/hi/ magazine/4942446.stm (accessed 5 Jun 2007).

10. England LJ, Levin RJ, Mills $\mathrm{JL}$, et al. Adverse pregnancy outcomes in snuff users Am J Obstet Gynecol 2003;189:939-43

11. Winn DM, Blot WJ, Shy C, et al. Snuff dipping and oral cancer among women in the southern United States. N Engl J Med 1981;304:745-9.

12. Idris AM, Ahmed HM, Malik MOA. Toombak dipping and cancer of the oral cavity in the Sudan: a case-control study. Int J Cancer 1995;63:477-80.

13. Rodu B, Cole P. Smokeless tobacco use and cancer of the upper respiratory tract. Oral Surg Oral Med Oral Pathol Oral Radiol Endod 2002;93:511-5.

14. Alguacil J, Silverman DT. Smokeless and other noncigarette tobacco use and pancreatic cancer: a case control study based on direct interviews. Cancer Epidemiol Biomarkers Prev 2004;13:55-8

15. Gupta PC, Mehta HC. Cohort study of all-cause mortality among tobacco users in Mumbai, India. Bull World Health Organ 2000;78:877-83.

16. Henley SJ, Thun MJ, Connell C, et al. Two large prospective studies of mortality among men who use snuff or chewing tobacco (United States). Cancer Causes Control 2005:16:347-58.

17. Accortt NA, Waterbor JW, Beall C, et al. Chronic disease mortality in a cohort of smokeless tobacco users. Am J Epidemiol 2002;156:730-7.

18. Accortt NA, Waterbor JW, Beall C, et al. Cancer incidence among a cohort of smokeless tobacco users (United States). Cancer Causes Control 2005;16:1107-15.

19. Sasco AJ, Merill RM, Dari I, et al. A case-control study of lung cancer in Casablanca, Morocco. Cancer Causes Control 2002;13:609-16.

20. Sapundzhiev N, Werner JA. Nasal snuff: historical review and health related aspects. J Laryngol Otol 2003;117:686-91.

21. Dygert HP. Snuff: a source of pathogenic bacteria in chronic bronchitis. N Eng J Med 1957:257:311-13.

22. Ayo-Yusuf OA, Van Wyk C, Van Wyk CW, et al. Smokeless tobacco products on the South African market do not inhibit oral bacterial flora: a pilot study. S African J Epidemiol Infect 2005;20:136-9.

23. Hummer B, Purnama I, Hahn HL. Stimulation of submucosal glands by nicotine applied locally to the airway mucosa. Klin Wochenschr 1988;66:161-9.

24. Ehrlich RI, White N, Norman R, et al. Predictors of chronic bronchitis in South Africa. Int J Tuberc Lung Dis 2004;8:369-76.

25. Medical Research Council. Respiratory symptoms questionnaire. London, UK: MRC, 1976.

26. Cerviri I, Accordini S, Verlato G, et al. Variations in the prevalence across countries of chronic bronchitis and smoking habits in young adults. Eur Respir J 2001;18:85-92.

27. Ayo-Yusuf 0A, Swart TJP, Ayo-Yusuf IJ. Prevalence and pattern of snuff dipping in a rural South African population. SADJ 2000:55:610-4.

28. Bjartveit K, Tverdal A. Health consequences of smoking 1-4 cigarettes per day. Tob Control 2005;14:315-20.

29. Simmons MS, Connett JE, Nides MA, et al. Smoking reduction and the rate of decline in FEV1: results from the Lung Health Study. Eur Respir J 2005;25:1011-17.

30. Sreedharan S, Kamath MP, Khadilkar U, et al. Effect of snuff on nasal mucosa. Am J Otolaryngol 2005;26:151-6.

31. Montnémery $\mathbf{P}$, Svensson C, Ädelroth E, et al. Prevalence of nasal symptoms and their relation to self-reported asthma and chronic bronchitis/emphysema. Eur Respir $J$ 2001:17:596-603. 
32. Randhawa K, Mendes E, Wanner A. Acute effect of cigarette smoke and nicotine on airway blood flow and airflow in healthy smokers. Lung 2006;184:363-8.

33. Hansson L, Choudry NB, Karlsson JA, et al. Inhaled nicotine in humans: effect on the respiratory and cardiovascular systems. J Appl Physiol 1994;76:2420-7.

34. Lee LY, Burki NK, Gerhardstein DC, et al. Airway irritation and cough evoked by inhaled cigarette smoke: role of neuronal nicotinic acetylcholine receptors. Pulm Pharmacol Ther 2007:20:355-64.

35. Aoshiba K, Nagai A, Yasui S, et al. Nicotine prolongs neutrophil survival by suppressing apoptosis. J Lab Clin Med 1996;127:186-94.

36. Hoidal JR. Pathogenesis of chronic bronchitis. Semin Respir Infect 1994;9:8-12.

37. Bolinder GM, Ahlborg BO, Lindell JH. Use of smokeless tobacco: blood pressure elevation and other health harzards found in a large-scale population survey. $J$ Int Med 1992;232:327-34.
38. Lander $\mathbf{F}$, Gravesen S. Respiratory disorders among tobacco workers. Br J Ind Med 1988:45:500-2.

39. Mustajbegovic J, Zuskin E, Schachter EN, et al. Occupational and environmental lung disease. Respiratory findings in tobacco workers. Chest 2003:123:1740-8.

40. Rodu B, Godshall WT. Tobacco harm reduction: an alternative cessation strategy for inveterate smokers. Harm Reduct J 2006;3:37.

41. Kozlowski LT, Strasser AA, Giovino GA, et al. Applying the risk/use equilibrium: use medical nicotine now for harm reduction. Tob Control 2001;10:201-3.

42. Ayo-Yusuf OA. Re-emergence of traditional tobacco products' usage in South Africa: an unintended consequence of existing tobacco control policy. African J Drug Alcohol Stud 2005;4:32-43.

43. Van Wyk CW. The oral lesion caused by snuff: a clinico-pathological study. Med Proc 1965;11:531-7.

\section{FUNDING AVAILABLE FOR RESEARCH PROJECTS}

The Committee on Publication Ethics (COPE) has established a Grant Scheme to fund research in the field of publication ethics. The Scheme is designed to provide financial support to any member of COPE for a defined research project that is in the broad area of the organisation's interests, and specifically in the area of ethical standards and practice in biomedical publishing. The project should have a specific goal and be intended to form the kernel of a future publication.

A maximum sum of $£ 5000$ will be allocated to any one project, but applications for smaller sums are welcomed.

The terms and conditions of the Grant are as follows:

- At least one of the applicants must be a member of COPE.

- Calls for applications will be made twice a year with closing dates of 1 December and 1 June. An electronic version of the application form must be sent to the Administrator no later than $12 \mathrm{pm}$ (noon GMT) on the closing date for consideration by COPE Council.

- The application must contain a lay summary of the project, a definition of the question to be posed, sufficient methodological detail to allow assessment of the viability of the project, a clear timeline and a definition of the likely deliverables. A full justification for the sum requested must accompany the application.

- A report on the progress of the research should be presented within one year of the award and at the end of the project. The grant must be used within two years from the date of award, and balance sheets must be forwarded annually. These should be sent to the Administrator. Any remaining funds after two years must be returned.

- It is anticipated that the work stemming from the project will be presented at one of COPE's annual seminar meetings within 2-3 years of the award. Such data may also be published in peer-reviewed journals. Any publications or related presentations at meetings by the recipient emanating in part or whole from COPE's support should be duly acknowledged and copies sent to the Administrator.

Applications are reviewed by a COPE sub-committee. Applicants will be advised of a decision as soon as practicable after the deadline date.

An application form can be obtained by contacting Linda Gough, COPE administrator, at LGough@ bmj.com or 0207383 6602. For more information on COPE, see http://www.publicationethics.org.uk/

The closing date for receipt of applications is 1 December 2007 or 1 June 2008. 